\title{
Signal Control Strategy for Supersaturated Traffic at Urban Road Intersections with a Large Technical Grade Gap
}

\author{
Baiqun Ding $\left(\mathbb{D},{ }^{1}\right.$ Liu Yang $\mathbb{D},{ }^{1,2} \mathrm{He} \mathrm{Xu}\left(\mathbb{D},{ }^{3}\right.$ and Yongming He $\mathbb{D}^{1}$ \\ ${ }^{1}$ School of Traffic \& Transportation, Northeast Forestry University, Harbin 150040, China \\ ${ }^{2}$ Changchun Municipal Engineering, Design \& Research Institute, Changchun 130033, China \\ ${ }^{3}$ Jiangsu Baisheng Engineering, Consultants Co. Ltd, Nanjing 211800, China
}

Correspondence should be addressed to Yongming He; hymjob@nefu.edu.cn

Received 22 September 2021; Revised 13 November 2021; Accepted 4 December 2021; Published 31 December 2021

Academic Editor: Jose E. Naranjo

Copyright ( 92021 Baiqun Ding et al. This is an open access article distributed under the Creative Commons Attribution License, which permits unrestricted use, distribution, and reproduction in any medium, provided the original work is properly cited.

To reduce the risk of queuing overflow on the urban minor road at the intersection under supersaturation where the capacity of the arterial and minor roads shows extreme disparity, reduce the adverse effects caused by long queues of vehicles on the minor road, and comprehensively balance the multiobjective requirements such as priority of the main road, queuing restrictions, and delay on the minor road, the minor road queue model at the end of red, a road remaining capacity model, and multiparameter coordinated signal control model were established, and a multiobjective genetic algorithm was used to optimize this solution. As an example, the multiparameter coordinated control strategy decreased the delay per vehicle by approximately $17 \%$ and the queue length by approximately $30 \%-50 \%$ on the minor road and slightly increased the delay per vehicle at the intersection and the length on the main road queue. This control strategy can make full use of the capacity of the main road to control the queue length on the minor road, effectively reduce the risk of minor road queue overflow blocking local road network traffic operation involved, and comprehensively balance the traffic demand between arterial and minor roads. It provides a reference control method for coping with the transfer of the main traffic contradiction under the oversaturated state of the road intersection with large disparity.

\section{Introduction}

Many urban primary and minor road intersections usually adopt the primary road priority control strategy to ensure the traffic capacity of the main road. However, at intersections with large technical level gaps between primary and minor roads, this control method will cause queued vehicles on minor roads to overtake when the traffic reaches supersaturation. As the signal cycle continues to accumulate, the minor road queue will be too long or even overflow, which interferes with or even "locks up" the upstream intersections, causing local road networks to involve traffic control failures and traffic operation paralysis.

When the supersaturated traffic state develops to a certain extent, the main contradiction of urban primary and minor road intersections transforms from ensuring traffic efficiency to avoiding traffic congestion and balancing traffic demand. At present, the number of two-way main roads with more than
8-10 lanes is increasing in many large cities. These roads have a large capacity and can accommodate more vehicles. How to make full use of the capacity of urban arterial roads to control the overflow caused by supersaturated traffic, balance the traffic demand of the primary and minor roads, and maintain the traffic operation and microcirculation of the local road network are questions worth considering.

The phenomenon of queue overflow can also be expressed as supersaturated traffic. Wu X took the green lost time and traffic efficiency at intersections as indicators for evaluating the severity of supersaturation. Many researchers have proposed different methods to calculate the queue length [1]. Wunderlich et al. used computer simulation to predict the maximum queue length when the intersection was in a steady-state flow [2]. Mirchandani and Zou established the steady state of vehicles based on a queuing theory of queue length calculation model for distribution [3]. Lin and Liu calculated the queuing length and delay time 
at intersections based on taxi positioning data, and the results obtained were applicable for noncongested road conditions [4].

Based on the queue length model, a variety of multiparameter signal control strategies were proposed. Aboudolas et al. regarded the parameters and constraints of signal control as a quadratic programming problem and balanced the queue length of each entrance at the intersection [5]. Li et al. established a multiobjective optimization model with the objectives of the shortest queue length, minimum delay, and minimum exhaust emissions and obtained the optimal timing scheme [6]. Reference [7] comprehensively considered the signal design of the upstream and downstream intersections, the turning flow, the length of the road section, and the phase difference. A method was then obtained for calculating the maximum queuing length at the intersection. Reference [8] proposed the concept and calculation method of the space-time coordination index of adjacent signalized intersections. Reference [9] calculated the signal control delay at the intersection by using the stop delay and acceleration or deceleration delay. Cheng Wei et al. proposed a traffic transfer method based on sensation control to solve the congestion problem caused by queue overflow in a certain direction [10].
The majority of the research on oversaturated intersections focused on the use of coordinated control of adjacent intersections to disperse greater queuing pressure to upstream intersections, but there were few studies involving multiparameter coordinated control at intersections with large and minor road capacities. Aiming at the adverse effects of excessively long vehicle queues on minor roads due to supersaturation, this study comprehensively coordinates the traffic capacity, queuing, and delays of primary and minor roads and establishes a well-directed control strategy for intersections on roads with large technical grade gaps.

\section{Queuing Calculation Model of the Red End on Minor Roads}

2.1. Model Establishment. On the basis of traffic wave theory and two-fluid theory, a queue length model at the end of the red light on a minor road was established, and the reliability of the model was verified by VISSIM simulation software.

2.1.1. Single-Lane Queue Length Model. The final number of vehicles in the queue at the entrance of a signalized intersection is equal to the sum of the number of vehicles detained in the previous cycle and the number of vehicles detained in this cycle, which can be expressed by

$$
\Delta N=N+N_{1}-\mathrm{N}_{2} \Delta \mathrm{N}_{\mathrm{r}}+\mathrm{C}=\mathrm{N}_{\mathrm{r}}+\mathrm{N}_{1 \mathrm{r}}+\mathrm{C}-\mathrm{N}_{2 \mathrm{r}}+\mathrm{C}=\mathrm{N}_{\mathrm{r}}+\mathrm{N}_{1 \mathrm{r}}-\mathrm{N}_{2 \mathrm{r}},
$$

where $N$ is the number of vehicles stuck in the entrance lane after the red light ends in the last cycle, pcu; $N_{1}$ is the number of vehicles entering the entrance lane from the start of the green light to the end of the red light in this signal cycle, pcu; $N_{2}$ is the number of vehicles leaving the entrance lane from the beginning of the green light to the end of the red light during this period, pcu; and $\Delta N$ is the total number of vehicles between the upstream and downstream sections of the entrance road at the end of the red light of this cycle, pcu.

Figure 1 shows the traffic state at the red light at the entrance of intersection B. $N$ represents the vehicles waiting in the line for release in the $L_{A}$ section, and the traffic density is approximately the congestion density, namely, $k_{j}$; $N_{1}$ is the number of vehicles entering the road section in this cycle, that is, the vehicles that are about to start queuing in the $L_{B}$ and $L_{C}$ sections. The $L_{C}$ section vehicles run normally, and the vehicles in the $L_{B}$ section start to decelerate and enter the queue. At this time, the density $k_{c}$ is between the optimal density $k_{m}$ and the jam density $k_{j}$, that is, $k_{m}<k_{c}<k_{j}$.

$\mathrm{N}_{2}$ is the number of vehicles leaving in this cycle. At this time, the density $k_{q}$ will start to decrease from the congestion density, so the maximum vehicle queue length in this cycle is as follows:

$$
L_{D}=\frac{N}{K_{m}}+\frac{N_{1}}{K_{C}}-\frac{N_{2}}{K_{q}},
$$

where $L_{D}$ is the queue length between the upstream and downstream sections at the end of red light, $\mathrm{km}$, and $k_{j}$ is the blocking density between the upstream and downstream sections, $\mathrm{pcu} / \mathrm{km}$.

When the traffic is in the optimal state of operation, the traffic density is the unobstructed density $k_{m}$, and the length of the road section between the upstream intersection and the downstream intersection is L. At this time, $\Delta N=k_{m} \cdot L$, and the queue length $L_{D}=0$. When a certain period of road conditions is completely blocked, the density is the blocking density $k_{j}$; at this time, $\Delta N=k_{j} \cdot L$, so the queue length $L_{D}=L$. Since $k_{m}<k<k_{j}$, equation (2) is applicable to the case where the density is between the best density and blocking density. Among them, $k_{j}, k_{c}$, and $k_{q}$ need to be calibrated according to actual conditions.

2.1.2. Multilane Queue Length Model. When the traffic flow becomes congested, the lane-changing situations are reduced. If the traffic density is higher and the compressibility of space is smaller, the interaction between lanes will be smaller. At this time, the multilane entrance can be regarded as a whole, and the overall queuing situation of the multilane entrance can be calculated using the queuing length model of the single-lane entrance at the intersection:

$$
\bar{L}_{D}^{\prime}=\frac{\sum_{i=1}^{n} L_{D}^{\prime}(i)}{n},
$$




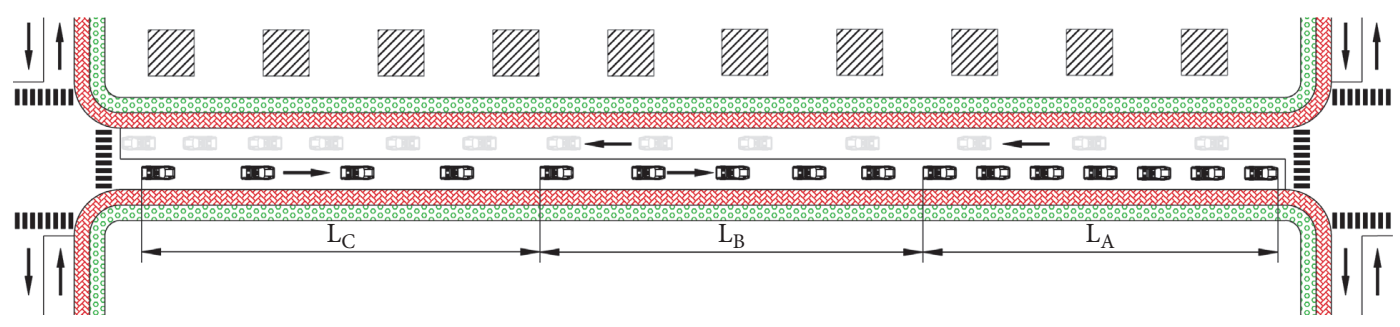

FIgURE 1: Traffic flow operation on the downstream queuing section.

where $\overline{L_{D}^{\prime}}$ is the average queuing length on the certain direction entrance of the intersection at the end of red in the current cycle, $\mathrm{km} ; L_{\mathrm{D}}^{\prime}(i)$ is the queuing length of lane $i$ in the cycle, $m$; and $n$ is the number of lanes in that direction at the intersection.

\subsection{Model Checking}

2.2.1. Parameter Test. The congestion density $k_{\mathrm{j}}$ is the traffic flow density when the speed is zero. This study sets up three different simulation schemes with VISSIM simulation software listed in Table 1 and discussed the value of blocking density. The simulation result is shown in Figure 2.

From the simulation results, the blocking densities $k_{j}$ of the three schemes were all approximately $160 \mathrm{pcu} / \mathrm{km}$, so $k_{j}=160 \mathrm{pcu} / \mathrm{km}$ was taken as the blocking density during simulation and verification of the model. According to the Greenberg logarithmic model given by (4), the best density $k_{m}$ was $59 \mathrm{~km} / \mathrm{h}$.

$$
k_{m}=\frac{k_{j}}{e} .
$$

At the beginning of the green light, the traffic density, $k_{q}$, of the $20 \mathrm{~m}$ section after the stop line (Figure 3) was between $90 \mathrm{pcu} / \mathrm{km}$ and $110 \mathrm{pcu} / \mathrm{km}$, and the average value of $k_{q}$ was $100 \mathrm{pcu} / \mathrm{km}$.

VISSIM does not have a clear approach to determining the position of $k_{c}$. Consequently, this study proposes an estimation method. Since $k_{m}<k_{c}<k_{j}$, and the longer $L_{A}$, the fewer vehicles traveling at critical speed $v_{m}$, and the closer $k_{c}$ approaches $k_{j}$, it is assumed that $k_{c}$ can be solved by (5):

$$
k_{c}=\frac{\left(k_{m}+k_{j}\right)}{2} \text {. }
$$

2.2.2. Simulation Program Settings. As shown in Figure 4, the simulation traffic flow direction was from intersection $\mathrm{A}$ to $\mathrm{B}$. Each lane was set to $500 \mathrm{~m}$ long and $3.25 \mathrm{~m}$ wide, with a saturation flow rate of $1,800 \mathrm{pcu} / \mathrm{h}$. The signal-phase timing parameters in this direction were set with the cycle $60 \mathrm{~s}$, green light $20 \mathrm{~s}$, red light $37 \mathrm{~s}$, and amber light $3 \mathrm{~s}$. The vehicle quantity detectors were set upstream of the entrance road, while the vehicle quantity detectors and queue counters were set downstream of the entrance road. The simulation time was $3,600 \mathrm{~s}$.

Continuous simulation for 60 cycles showed that the vehicle queue started from the 10th cycle, and the 30th cycle started to be stable. To make the test results more stable, the 41 st to 60 th cycles were chosen as the simulation experiment range with an equivalent difference in the range of $\pm 13 \mathrm{~m}$ and a relative error less than $\pm 5 \%$ between the simulated and calculated queuing length. The calculated value of the model was very close to the simulated queuing length of VISSIM.

The tracking error $\sigma$ is used to describe the deviation between the calculated value of the model and the simulated value. The smaller the deviation is, the more reliable the model is. Generally, the model is reliable when the deviation is less than 10 .

$$
\sigma=\sqrt{\frac{\sum_{i}^{M}\left(L_{m i}-L_{\mathrm{e} i}\right)^{2}}{M}},
$$

where $L_{m i}$ is the queue length calculated by the model, $m ; L_{e i}$ is the queue length of the simulation test, $m$; and $M$ is the number of cycles.

The calculated tracking errors $\sigma$ of the single- and double-lane models set in this study were 6.78 and 9.11, respectively. Thus, the model can be considered reliable.

\section{Switching Threshold of the Signal Control Scheme}

3.1. Prediction Model for the Remaining Capacity of the Road Section. The maximum capacity of a road section refers to the maximum number of vehicles that can be accommodated under existing traffic conditions. The remaining capacity of the road section between adjacent intersections is one of the important parameters for determining the signal control plan of the downstream intersection. The remaining road capacity can be obtained by calculating the length of the red end of the entrance lane in this direction [11].

3.1.1. Total Road Capacity. Taking the urban road section between adjacent intersections as the research object, the total length of the road section is $L$, and the upstream and downstream intersections are named $A$ and $B$, respectively, as shown in Figure 5.

The total capacity of this section is as follows:

$$
Q=\left(\left[\frac{L-l}{l+h}\right]+1\right) \times n,
$$

where $Q$ is the total capacity of the road section, pcu; $L$ is the total length of the road section, $m$; $l$ is the equivalent length of a standard car, $m$; $h$ is the average space between the rear 
TABle 1: Simulation scheme setting.

\begin{tabular}{lccc}
\hline Scheme & Length of road section $(\mathrm{m})$ & Width of vehicle lane $(\mathrm{m})$ & Quantity of vehicle lane \\
\hline 1 & 200 & 3.25 & 1 \\
2 & 400 & 3.25 & 1 \\
3 & 400 & 3.5 & 2 \\
\hline
\end{tabular}

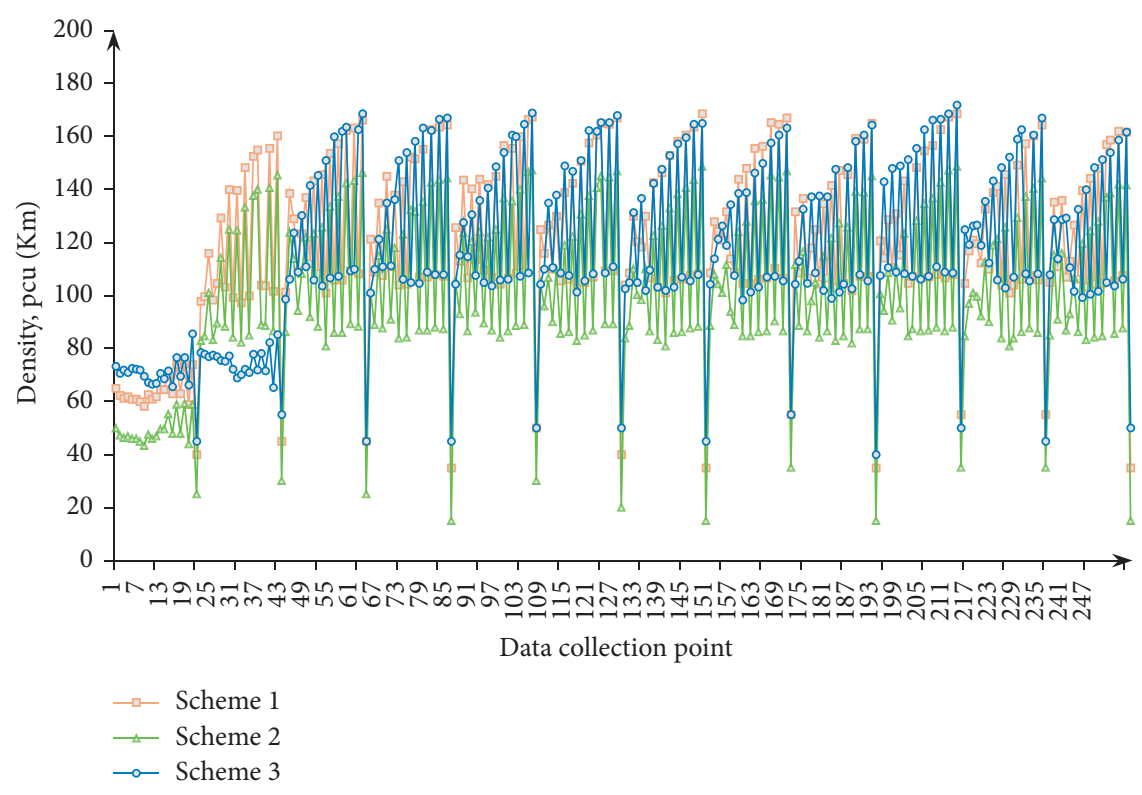

FIgURE 2: Traffic density simulation data.

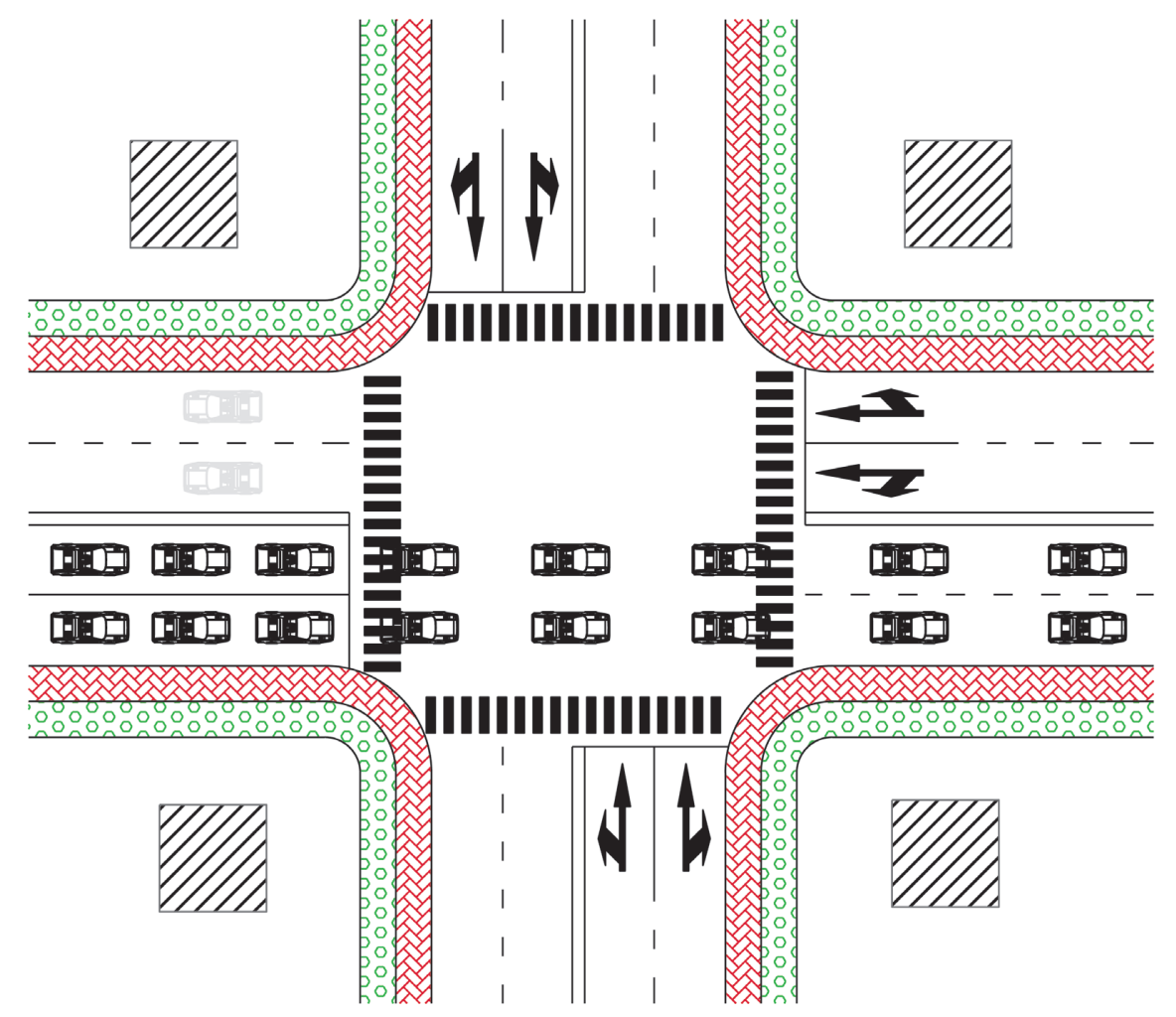

Figure 3: Traffic density at the intersection. 


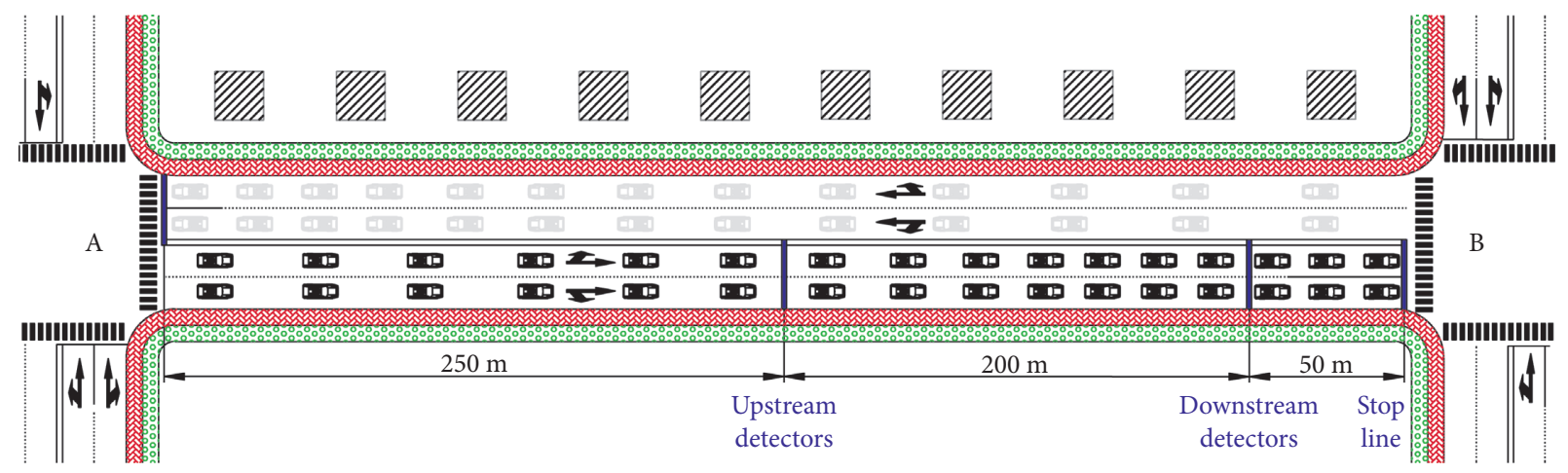

FIgURE 4: Simulation model and detector settings.

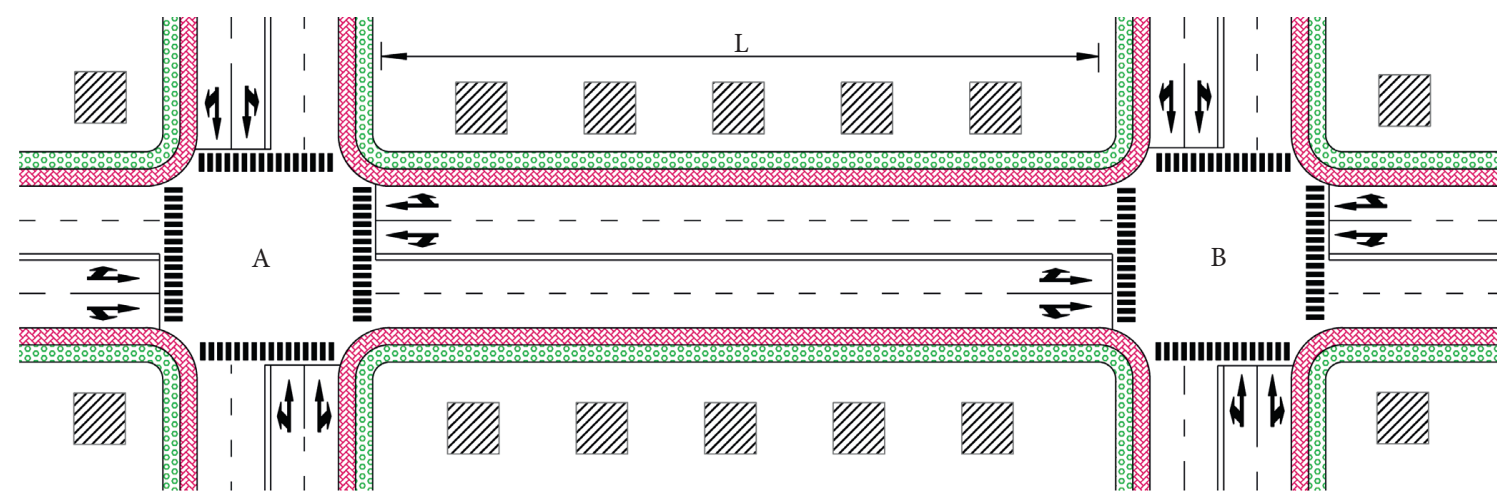

Figure 5: The road section being studied.

of the front vehicle and the head of the rear vehicle, $m ; n$ is the number of lanes in a certain direction of the road section; and $[L-l / l+h]$ represents the integer of $L-l / l+h$.

3.1.2. Road Capacity Occupied by Queued Vehicles. From the above analysis, it can be seen that if the length of the vehicle queue on the road segment is $L^{\prime}$, then the capacity of the road segment occupied by the vehicle queue is as follows:

$$
Q_{0}=\left(\left[\frac{L^{\prime}-l}{l+h}\right]+1\right) \times n
$$

where $Q_{0}$ is the road capacity occupied by queued vehicles, $\mathrm{pcu} ; L^{\prime}$ is the vehicle queue length on the road section, $m$.

3.1.3. Remaining Capacity of the Road Section. The remaining capacity of the road section can be obtained by two methods. One is obtained by calculating the difference between the total and occupied capacity shown in (9):

$$
Q_{r}=Q-Q_{0}=\left(\left[\frac{L-l}{l+h}\right]+1\right) \times n-\left(\left[\frac{L^{\prime}-l}{l+h}\right]+1\right) \times n,
$$

where $Q_{r}$ is the remaining capacity of the road section, pcu.

The other is to calculate the length of the unoccupied road section through the vehicle queue length, and the number of vehicles that can be accommodated in this length is the remaining capacity of the road section. The length of the unoccupied section is as follows:

$$
L^{\prime \prime}=L-\mathrm{L}^{\prime}
$$

where $L^{\prime \prime}$ is the unoccupied length of the road section, $m$.

The remaining capacity is as follows:

$Q_{r}=\left(\left[\frac{L^{\prime \prime}-l}{l+h}\right]+1\right) \times n=\left(\left[\frac{L-L^{\prime}-l}{l+h}\right]+1\right) \times n$.

3.2. Control Scheme Conversion Threshold. To avoid local road network traffic paralysis caused by queuing overflow of minor roads, when the queue length and remaining capacity of minor roads reach a certain limit, the general control mode of main road priority should be adjusted to reduce the minor road queuing length and the overflow risk; when the queue length is reduced to a certain extent, the main road priority control mode could be returned.

If the remaining capacity of the minor road in a certain cycle of the signal-controlled intersection is equal to or even less than the number of vehicles entering the minor road from the upstream intersection, that is, when $Q_{r} \leq N_{1}$, queuing overflow will cause the upstream intersection of the minor road to lock up to determine the critical value of the scheme conversion. It is combined with (11). 


$$
L^{\prime} \geq L-l-\frac{\left(N_{1}-n\right)(l+h)}{n},
$$

where $N_{1}$ is the number of vehicles arriving in the next cycle, pcu.

The ratio $y_{1}$ of queue length to road capacity is taken as the criterion to determine whether or not the minor route is released, namely,

$$
y_{1}=\frac{L^{\prime}}{Q},
$$

where $y_{1}$ is the capacity matching ratio, $\mathrm{m} / \mathrm{pcu}$.

Equations (12) and (13) are combined to obtain the control scheme conversion threshold $\left[y_{1}\right]$ based on the prediction model of minor road residual capacity.

$$
y_{1} \geq\left[y_{1}\right]=\frac{\left[n(L-l)-\left(N_{1}-n\right)(l+h)\right][l+h]}{n^{2}(L+h)} .
$$

\section{Multiparameter Coordinated Control Model for Primary and Minor Roads}

4.1. Control Conditions. The research object is an urban intersection signalized with four-phase and permanent cycle time. The signal optimization scheme studied in this section is suitable for intersections where the minor roads are in an oversaturated state. A multiobjective optimization function to coordinate the vehicle queue length between the primary and minor roads and minimize the total delay at the intersection was established and solved by a genetic algorithm. The queue length at the intersection adopted the above-mentioned calculation method.

\subsection{Multiobjective Optimization Model of the Signal Control}

4.2.1. Multiobjective Optimization Genetic Algorithm. The mathematical model of the multiobjective optimization problem is as follows:

$$
\left\{\begin{array}{l}
V_{\min } f(x)=\left[f\left(x_{1}\right), f\left(x_{2}\right), \cdots f\left(x_{n}\right)\right]^{T}, \\
\text { s.t. } x_{i} \in X \\
X \subseteq R^{m}
\end{array}\right.
$$

where $V_{\text {min }}$ is the vector minimization, and namely, the subobjective functions in the vector objective function $f(x)$ are minimized as much as possible.

4.2.2. Weight Coefficient Method Conversion. For a multiobjective optimization problem, if each subobjective function $f_{i}(x)(i=1,2, \ldots, n)$ is given a weight $\omega_{i}(i=1,2, \ldots, n)$, where $\omega_{i}$ is the corresponding $f_{i}(x)$ in the importance of the multiobjective optimization function, then the linear weighted sum of each subobjective function $f_{i}(x)$ can be expressed as follows:

$$
u=\sum_{i=1}^{n} \omega_{i} f_{i}(x)
$$

If $u$ is used as the evaluation function of the multiobjective optimization problem, the multiobjective optimization problem can be transformed into a single-objective optimization problem, and the single-objective optimization genetic algorithm can be used to solve the multiobjective problem.

\subsection{Optimization Objective Function and Intersection Model}

4.3.1. Delay Model at Signalized Intersections. Vehicle delay at intersections refers to the loss of travel time caused by vehicles being controlled by signals at intersections. According to the research, deterministic queuing theory is applicable to the delay evaluation of oversaturated intersections where the vehicle arrival rate is greater than the capacity [12]. The calculation formula is as follows [13]:

$$
\begin{aligned}
& p=\frac{N}{q}, \\
& y=\frac{(p-1) N T}{2}, \\
& d=\frac{R}{2}+\frac{y p}{q},
\end{aligned}
$$

where $N$ is capacity, $\mathrm{pcu} / \mathrm{h} ; q$ is traffic arrival rate; $p$ is saturation; $d$ is average delay per vehicle in each lane, $s ; R$ is red light time, $s ; y$ is average supersaturated per hour number of stranded vehicles, $\mathrm{pcu} / \mathrm{h}$; and $T$ is the duration of the investigation, generally $15 \mathrm{~min}$.

The average delay of each entrance is calculated according to the weighted average of the vehicle delays in each lane of the entrance:

$$
d_{j}=\frac{\sum_{i} d_{i j} q_{i j}}{\sum_{i} q_{i j}}
$$

where $d_{j}$ is the average delay of each vehicle in each entrance, $s ; d_{i j}$ is the average delay per vehicle of Lane $i$ in entrance $j, s$; and $q_{i j}$ is the vehicle arrival rate in lane $i$ of entrance $j, \mathrm{pcu} / \mathrm{h}$.

The average delay per vehicle in a signal cycle at a certain intersection is the weighted average of the delays of each entrance.

$$
d_{I}=\frac{\sum_{j} d_{j} q_{j}}{\sum_{j} q_{j}}
$$

where $d_{I}$ is the average delay of each vehicle at the intersection, $s ; q_{j}$ is the vehicle arrival rate in entrance $j, \mathrm{pcu} / \mathrm{h}$.

4.3.2. Queue Balancing Strategy. The vehicle queue length balancing strategy allocates more green time to the direction where the ratio of queue length to capacity is large to avoid long queue or overflow in a certain direction (usually on minor roads) to disperse the long queue of vehicles in a 
timely manner and prevent more serious traffic problems [14].
According to the above thoughts, the control objective of a spot signalized intersection can be briefly described as follows:

$$
\begin{aligned}
& \overline{L_{i}^{\prime}}=\frac{L_{1}^{\prime}+L_{2}^{\prime}+L_{3}^{\prime}+L_{4}^{\prime}}{4}, \\
& L_{E}=\min \left[\left(\frac{L_{1}^{\prime}-\overline{L_{i}^{\prime}}}{L_{1}}\right)^{2}+\left(\frac{L_{2}^{\prime}-\overline{L_{i}^{\prime}}}{L_{2}}\right)^{2}+\left(\frac{L_{3}^{\prime} \overline{L_{i}^{\prime}}}{L_{3}}\right)^{2}+\left(\frac{L_{4}^{\prime}-\overline{L_{i}^{\prime}}}{L_{4}}\right)^{2}\right],
\end{aligned}
$$

where $L_{E}$ is the balanced performance index of queuing length; $L_{i}^{\prime}$ is the queuing length at the end of red of each entrance, $m$; and $L_{i}$ is the length of the road section.

4.3.3. Multiobjective Optimization Model. The objective function is that the average delay of vehicles tends to be minimal, and the queue length of each entrance tends to balance at the intersection. The weighted coefficient method is used to transform the dual-objective function into a single-objective function. The optimization conditions and constraints are as follows:

$$
\begin{aligned}
& F(x)= \min \left[\alpha \frac{d_{O}}{d_{I}}+\beta \frac{L_{O}}{L_{E}}\right], \\
& \text { s.t. }\left\{\begin{array}{l}
C_{\min } \leq C \leq C_{\max }, \\
g_{i_{\min }} \leq g_{i} \leq g_{i_{\max }} \\
d_{I}=\frac{\sum_{j} d_{j} q_{j}}{\sum_{j} q_{j}}, \\
L_{E}=\min \left[\left(\frac{L_{1}^{\prime}-\overline{L_{i}^{\prime}}}{L_{1}}\right)^{2}+\left(\frac{L_{2}^{\prime}-\overline{L_{i}^{\prime}}}{L_{2}}\right)^{2}+\left(\frac{L_{3}^{\prime}-\overline{L_{i}^{\prime}}}{L_{3}}\right)^{2}+\left(\frac{L_{4}^{\prime}-\overline{L_{i}^{\prime}}}{L_{4}}\right)^{2}\right], \\
L_{i}{ }^{2} \leq L_{i}, \\
\alpha+\beta=1,
\end{array}\right.
\end{aligned}
$$

where $\alpha$ and $\beta$ are weighting coefficients; $d_{O}$ and $L_{O}$ are the performance indicators for the average delay of vehicles at intersections and the line length balance of the optimized timing plan; $d_{\mathrm{I}}$ is the average delay of vehicles at the intersections of the original timing plan; $L_{E}$ is the balanced performance index of queuing length; $C$ is the signal period, $s$; and $g_{i}$ is the effective green light duration, $s$.

\section{Case Study of an Intersection}

5.1. Current Situation of Intersections. The intersection of Zhengyi Road and Keyan Street in the Harbin urban area was taken as a study case. Zhengyi Road is in the north-south direction with 12 two-way lanes, and Keyan Street is in the east-west direction with 4 two-way lanes. It is a typical intersection of primary and minor roads with a large capacity gap. The basic situation is shown in Table 2. There are three signal phases at the crossing: one phase is going straight in the north-south direction, one phase is turning left in the north-south direction, and the other phase is going straight and turning left in the east-west direction. The signal timing plan is shown in Figure 6.

Part of the traffic data collected by the video observation analysis method is shown in Table 3.

Detectors are set at the beginning and end of the entrance lane of the intersection to observe and record the number of vehicles passing by the detectors; therefore, the average queuing length of each entrance lane of the intersection can be obtained. Table 4 shows the average value of multiperiod data. 
TABle 2: The condition of each entrance at the intersection.

\begin{tabular}{lccc}
\hline Entrance driveway & Distance from the upstream intersection $(\mathrm{m})$ & Grade of road & Number of lanes \\
\hline West entrance & 600 & Minor road & 2 \\
East entrance & 600 & Primary road & 2 \\
South entrance & 1100 & 1200 & 5 \\
North entrance & & 7 \\
\hline
\end{tabular}

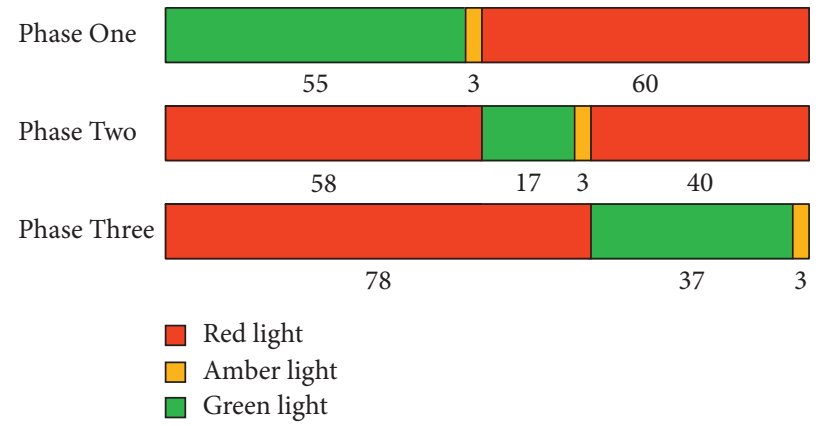

FIgURE 6: Timing scheme of intersection.

TABLE 3: Traffic volume and performance indicators at the intersection.

\begin{tabular}{|c|c|c|c|c|c|c|c|}
\hline $\begin{array}{l}\text { Intersection } \\
\text { entrance }\end{array}$ & $\begin{array}{c}\text { Lane } \\
\text { direction }\end{array}$ & $\begin{array}{l}\text { Min traffic volume } \\
(\mathrm{pcu})\end{array}$ & $\begin{array}{l}k \text { hour traffic volume } \\
(\mathrm{pcu} / \mathrm{h})\end{array}$ & $\begin{array}{l}\text { Saturation flow rate } \\
(\mathrm{pcu} / \mathrm{h})\end{array}$ & $\begin{array}{c}\text { Green } \\
\text { split }\end{array}$ & $\begin{array}{l}\text { Flow rate } \\
\text { ratio }\end{array}$ & Saturation \\
\hline \multirow[b]{2}{*}{ West entrance } & Straight-left & 171 & 684 & 1636 & 0.31 & 0.42 & 1.33 \\
\hline & $\begin{array}{l}\text { Straight- } \\
\text { right }\end{array}$ & 174 & 696 & 1636 & 0.31 & 0.43 & 1.36 \\
\hline \multirow[b]{2}{*}{ East entrance } & Straight-left & 156 & 624 & 1636 & 0.31 & 0.38 & 1.22 \\
\hline & $\begin{array}{l}\text { Straight- } \\
\text { right }\end{array}$ & 162 & 648 & 1636 & 0.31 & 0.40 & 1.26 \\
\hline \multirow{7}{*}{ South entrance } & $\begin{array}{l}\text { Straight- } \\
\text { right }\end{array}$ & 216 & 864 & 1636 & 0.47 & 0.53 & 1.13 \\
\hline & Straight & 210 & 840 & 1636 & 0.47 & 0.51 & 1.10 \\
\hline & Straight & 207 & 828 & 1636 & 0.47 & 0.51 & 1.09 \\
\hline & Straight & 213 & 852 & 1636 & 0.47 & 0.52 & 1.12 \\
\hline & Straight & 216 & 864 & 1636 & 0.47 & 0.53 & 1.13 \\
\hline & Left & 36 & 144 & 1636 & 0.14 & 0.09 & 0.61 \\
\hline & Left & 30 & 120 & 1636 & 0.14 & 0.07 & 0.51 \\
\hline \multirow{5}{*}{ North entrance } & $\begin{array}{l}\text { Straight- } \\
\text { right }\end{array}$ & 204 & 816 & 1636 & 0.47 & 0.50 & 1.07 \\
\hline & Straight & 210 & 840 & 1636 & 0.47 & 0.51 & 1.10 \\
\hline & Straight & 216 & 864 & 1636 & 0.47 & 0.53 & 1.13 \\
\hline & Straight & 204 & 816 & 1636 & 0.47 & 0.50 & 1.07 \\
\hline & Left & 39 & 156 & 1636 & 0.14 & 0.10 & 0.66 \\
\hline
\end{tabular}

TABLE 4: The average queue length of each entrance at the intersection.

\begin{tabular}{lcccc}
\hline $\begin{array}{l}\text { Intersection } \\
\text { entrance }\end{array}$ & $\begin{array}{c}\text { Number of vehicles } \\
\text { remaining }(\mathrm{pcu})\end{array}$ & $\begin{array}{c}\text { Number of vehicles arriving } \\
\text { upstream }(\mathrm{pcu})\end{array}$ & $\begin{array}{c}\text { Number of vehicles leaving } \\
\text { downstream }(\mathrm{pcu})\end{array}$ & $\begin{array}{c}\text { Queue length } \\
(\mathrm{m})\end{array}$ \\
\hline West entrance & 165 & 40 & 35 & 511 \\
East entrance & 105 & 38 & 32 & 332 \\
South entrance & 211 & 146 & 135 & 191 \\
North entrance & 133 & 113 & 108 & 166 \\
\hline
\end{tabular}


TABle 5: Delay data at the intersection.

\begin{tabular}{lcc}
\hline Intersection entrance & Average delay per vehicle of the approaches/ (s) & Average delay per vehicle of the intersection/ (s) \\
\hline West entrance & 48.07 & 38.22 \\
East entrance & 45.49 & \\
South entrance & 35.70 & 34.93
\end{tabular}

TABLE 6: Value range of weight coefficient.

\begin{tabular}{lccccc}
\hline Service level of main road & $\alpha$ & $\beta$ & Service level of main road & $\alpha$ & $\beta$ \\
\hline High service level (A or B) & 0.3 & 0.7 & Low service level (E or F) & 0.7 & 0.3 \\
Medium service level (C or D) & 0.5 & 0.5 & - & - & - \\
\hline
\end{tabular}

The average delay per vehicle of each entrance and average delay per vehicle of the intersection were calculated by (17-21), and the results are shown in Table 5 .

\subsection{Optimization Algorithm Solution}

5.2.1. The Judgment of Scheme Conversion. The parameters of queuing length and road capacity involved in (13) mainly include $L^{\prime}, l, h$, and $n$. The equivalent length of vehicle $l$ was $6 \mathrm{~m}$, and the average space between the rear of the front vehicle and the head of the rear vehicle $h$ was $2 \mathrm{~m}$. According to Table 4 , the average queuing length of the west entrance $L^{\prime}$ was $511 \mathrm{~m}$, and the number of lanes $n$ was 2 . The appropriate capacity matching ratio $y_{1}$ was calculated as $3.4 \mathrm{~m} / \mathrm{pcu}$.

The average number of vehicles entering the entrance lane from the start of the green light to the end of the red light in this signal cycle $N_{1}$ was $40 \mathrm{pcu}$. By substituting the parameters into (14), the transition threshold $\left[y_{1}\right]$ was calculated to be 2.9; hence, $y_{1}=3.4>\left[y_{1}\right]=2.9$. The traffic flow state met the standard of scheme conversion, so the control method proposed in this study can be used.

5.2.2. Determination of Weight Coefficient. The value of the weight coefficients $\alpha$ and $\beta$ in the optimization algorithm to solve the problem is usually determined by the service level provided by the main road. If the service level of the main road is relatively high, reducing the queue length of the minor road should be the main improvement index, that is, $\alpha<\beta$. If the service level of the main road is poor, reducing the road delay should be the main improvement index, and reducing the queue length will become a secondary factor, that is, $\alpha>\beta$. When the service level is medium, $\alpha=\beta$. The value range is shown in Table 6 [6].

Analyzing the intersection of Zhengyi Road and Keyan Street, the average delay of imported vehicles from the north was $34.93 \mathrm{~s}$, and the corresponding service level was C; the average delay of imported vehicles from the south was $35.70 \mathrm{~s}$, and the corresponding service level was D. Therefore, $\alpha=0.5, \beta=0.5$.

5.3. Comparison before and after Optimization. The collected data were input into the optimization model and solved by a genetic algorithm to obtain the optimized signal timing

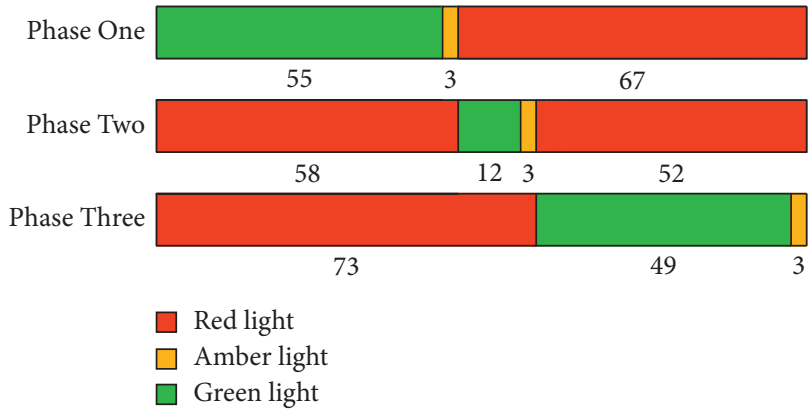

FIgUre 7: Optimized timing scheme of intersection.

scheme (as shown in Figure 7) and the average vehicle delay and queue length of the intersection under the timing scheme (as shown in Table 7). The applicability and effect of the model were tested by comparing the delay and queue length before and after optimization.

Table 7 shows that the average delay per vehicle on the main road in the north-south direction increased by approximately $16.7 \%$, and the average queue length increased by $8.4 \%-11.4 \%$. At the same time, the average delay per vehicle on the minor road in the east-west direction decreased by approximately $16.9 \%$. The average queue length was significantly reduced by $31.5 \%-50 \%$; the average delay per vehicle at the intersection increased by $6.44 \%$. Figures $8(\mathrm{a})$ and $8(\mathrm{~b})$ show the variations in various indicators before and after coordinated optimization.

Under the original control scheme, the queue length at the west entrance was close to the full length of the road section, while the queue length at the east entrance was close to $2 / 3$ of its own road section length. Therefore, there were risks of an overflow caused by overlong queues in both entrances of the minor road. After optimization, the queue length of the west entrance was reduced to approximately $1 / 2$ of the length of the road section in its direction, and the queue length of the east entrance was reduced to approximately $1 / 6$ of the length of the road section in its direction, which greatly reduced the risk of queue overflow. Regardless of whether the signal scheme was optimized, the queue length of the main road remained approximately $1 / 5$ of the length of its own road section, and the road load in this direction did not significantly increase. It can be thus considered that the optimization effect was relatively 


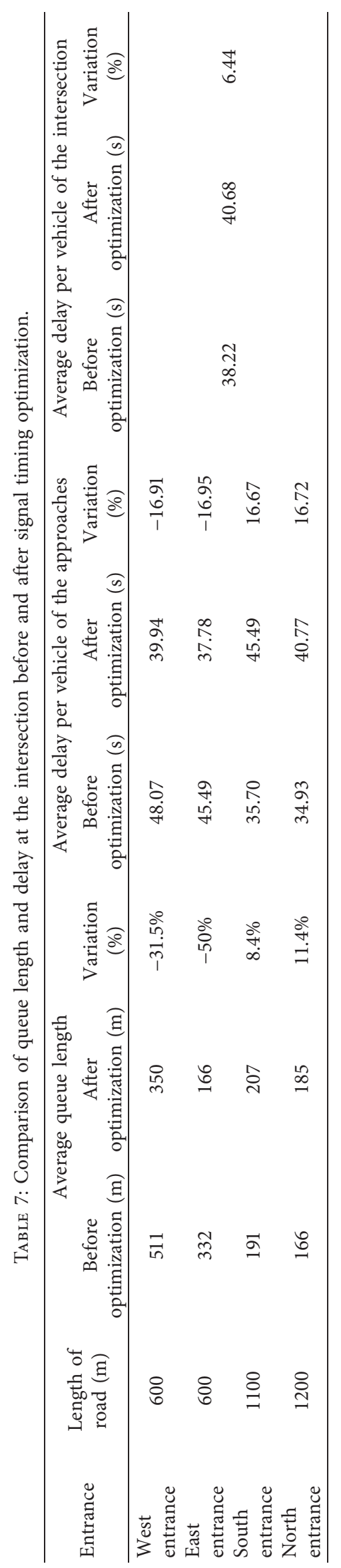




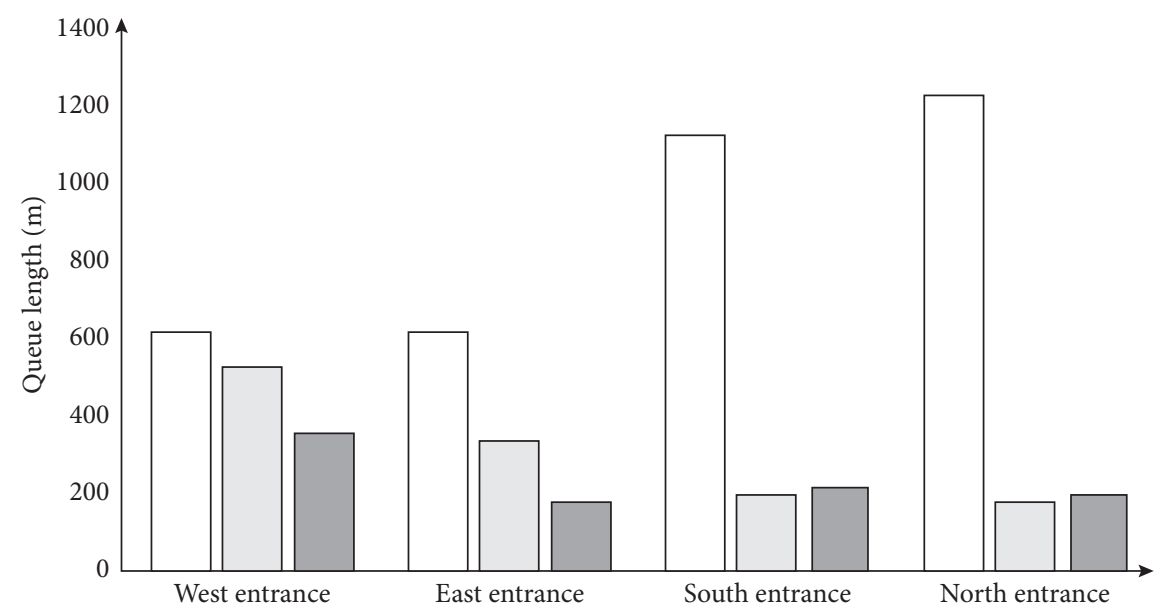

Entrance driveway

Length of road section

Average queue length before optimization

Average queue length after optimization

(a)

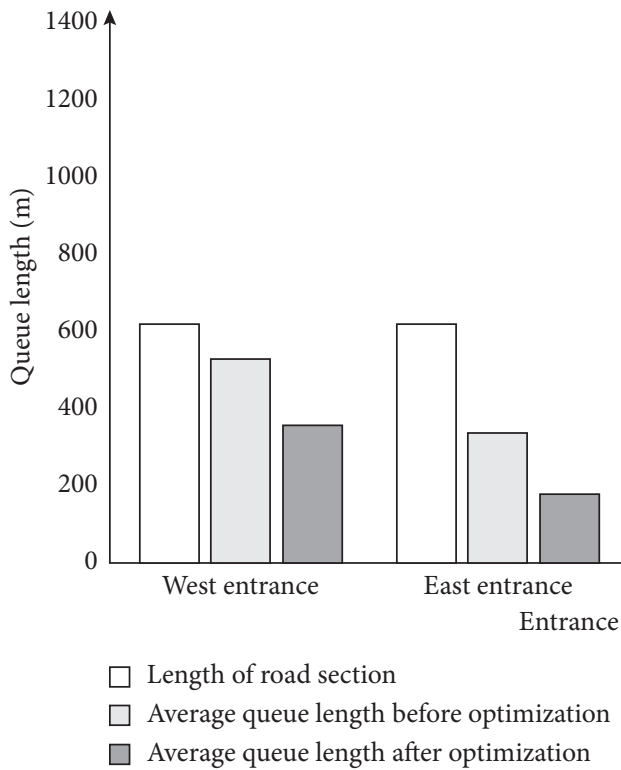

(b)

FiguRE 8: Comparison of traffic performance index before and after the signal control optimization at the intersection. (a) Average delay per vehicle. (b) Average queue length.

balanced, and the optimization scheme was reasonable and effective.

\section{Conclusions}

Through theoretical research, simulation experiments, and case analysis, the following conclusions can be drawn:

(1) When the supersaturated traffic flow continues to develop to a certain extent, the main contradiction of the intersection with the large capacity disparity between the primary and minor road will change from ensuring traffic efficiency to avoiding local traffic blocking and balancing traffic demand, and the control strategy should also be accordingly changed. The multiparameter coordinated control method comprehensively considers the capacity, delay, queue length, and service level of the main and minor roads, which helps to make full use of the capacity of the main road to control the minor road queuing length and queue overflow risk and balance the traffic demand of the primary and minor roads.

(2) The case study showed that the average delay per vehicle at the intersection with multiparameter coordinated control increased by $6.44 \%$, and the queue length of the main road increased by $8 \%-11 \%$. However, the average delay per vehicle decreased by 
approximately $17 \%$ and the queue length decreased by $30 \%-50 \%$ on minor roads. The results show that the optimization method can significantly reduce the minor road queuing length and delay while slightly increasing the queuing length on the main road and the average delay per vehicle at the intersection, avoiding the traffic jam of the local road network caused by queuing overflow, and the control effect is relatively balanced and reasonable.

\section{Data Availability}

The data used to support the findings of this study are available from the corresponding author upon request (e-mail: hymjob@nefu.edu.cn).

\section{Conflicts of Interest}

The authors declare that they have no conflicts of interest regarding the publication of this study.

\section{Acknowledgments}

The authors would like to thank the director of the laboratory, Li Shaoyan, for providing the experimental equipment and Professor Cheng Yang of the University of Wisconsin for the calculation method. The authors would like to thank the teachers and graduate students of the transportation research center of the Northeast Forestry University for their help. This work was supported by the Natural Science Foundation of Heilongjiang Province, China, grant no. LH2019E004 and the National Natural Science Foundation of China, grant no. 71771047.

\section{References}

[1] X. Wu, H. X. Liu, and D. Gettman, "Identification of oversaturated intersections using high-resolution traffic signal data," Transportation Research Part C: Emerging Technologies, vol. 18, no. 4, pp. 626-638, 2010.

[2] R. Wunderlich, I. Elhanany, and T. Urbanik, "A stable longest queue first signal scheduling algorithm for an isolated intersection," in Proceedings of the 2007 IEEE International Conference on Vehicular Electronics and Safety, pp. 1-6, Beijing, China, December 2007.

[3] P. B. Mirchandani and N. Zou, "Queuing models for analysis of traffic adaptive signal control," IEEE Transactions on Intelligent Transportation Systems, vol. 8, no. 1, pp. 50-59, 2007.

[4] H. Lin and D. Liu, "Study of Queue Length and Delay Calculation Based on Taxi GPS Data," in Proceedings of the Eleventh International Conference Of Chinese Transportation Professionals (ICCTP), pp. 1379-1390, Nanjing, China, August. 2011.

[5] K. Aboudolas, M. Papageorgiou, A. Kouvelas, and E. Kosmatopoulos, "A rolling-horizon quadratic-programming approach to the signal control problem in large-scale congested urban road networks," Transportation Research Part C: Emerging Technologies, vol. 18, no. 5, pp. 680-694, 2010.

[6] Z. Li, W. Dong, J. Han, and M. Zhu, "Multi-object optimization for intersection signal control based on genetic algorithm," Journal of Computer Applications, vol. 36, no. S2, pp. 82-84+88, 2016.

[7] J. Wang, X. Guo, and Z. Zou, "Calculation of queue length about signal design of upstream intersection," Journal of Wuhan University of Technology, vol. 39, no. 1, pp. 21-24+29, 2015.

[8] J. Wang, Y. Bai, and X. Yang, "Queue length calculation model at adjacent signal intersections," Journal Of Tongji University, vol. 40, no. 11, pp. 1634-1640, 2015.

[9] J. Wang, Z. Zou, H. Ge, and Z. Zhou, "Intersection delay considering about up-stream signal," Journal of Transportation Systems Engineering and Information Technology, vol. 15, no. 1, pp. 75-80, 2015.

[10] W. Cheng, Y. Tang, and Z. Zheng, "Research on the method of flow transfer based on actuated control at over-saturated intersection," Journal of Chongqing Jianzhu University, vol. 37, no. 11, pp. 83-90, 2018.

[11] M. Li, Research on Traffic Signal Control Method of Prevent Overflow of Intersection, Harbin Institute of Technology, Harbin, China, 2015.

[12] H. Zhao, R. He, and F. Jia, "Vehicle energy consumption at oversaturated intersection using fixed number theory," Journal of Transportation Systems Engineering and Information Technology, vol. 17, no. 5, pp. 75-81, 2017.

[13] Y. Cai, D. Sun, and G. Tang, "Study on section delay model under widening zone queue overflow condition," Journal of Highway and Transportation Research and Development, vol. 33, no. 6, pp. 123-127, 2016.

[14] J. Hao, Z. Hou, and X. Liu, "Vehicle queuing length balancedcontrol of the signalized isolated intersection via multiparametric programming," Control and Decision, vol. 28, no. 4, pp. 595-599, 2013. 